\title{
U.S. INTRA-STATE GEOGRAPHIC VARIATION IN PSYCHOLOGICAL CHARACTERISTICS AND STATE FISCAL SHORTFALLS
}

\author{
William Provaznik \\ Department of Management, Central Washington University, Ellensburg, WA, USA
}

Received 2014-09-18; Revised 2014-10-10; Accepted 2014-12-02

\begin{abstract}
This study extends on personality literature by examining state level variation of the Big Five Personality traits, per-capita GDP and population on US state budget shortfalls. Through the lens of Wildavsky's Cultural Theory of Budgeting, this study analyzes state level Big Five personality characteristics and their relationship to budgetary shortfalls. Significant relationships between per-capita GDP, agreeableness, conscientiousness, neuroticism and openness to new experience with state budget gaps were observed. An interaction effect between conscientiousness and agreeableness was also observed. This study links the aggregated individual personality of a state's population to the outcomes of its policy making. Policy makers benefit from understanding the relationship between the personalities of their constituencies and the nature of the policies they are implementing.
\end{abstract}

Keywords: Intra-State Variation, Fiscal Shortfalls, Psychological Characteristics

\section{INTRODUCTION}

With governments still reeling from the effects of "The Great Recession", fiscal survival has become increasingly challenging for state and local governments. Municipalities are more at risk of catastrophic budget shortfalls, having to resort to cuts in services and frantic searches for new avenues for increasing taxes, as well as seeking ways to skirt legal barriers to declaring bankruptcy (Eide, 2013). Such concern for government fiscal management extends to state governments as well. Many states have seen downgrades in their credit ratings due to budget problems or overall economic weakness, leading to increased borrowing costs and questions about their ability to service debt.

Sharing his reasoning for closing guarantor positions in municipal bonds, which sent the bond market into a major sell-off, Warren Buffet recently noted the growing urgency for remedying budget commitments made by past state and local government officials (Buffet, 2013). Although it is important to identify both successful and failed initiatives and to prioritize the government's allocation of scarce resources, a review of higher level factors which influence fiscal conditions is needed.

One of these factors is the particular personality composition of the states which influences the legislators, governors and their constituents' perceptions of what is important and how they interpret the situations they face. While much work has been done linking personality to individual and organizational outcomes, a paucity of research has examined a relationship between state level personality traits and fiscal viability. This paper extends previous work on personality and state government fiscal viability by examining its relationship to the "Big Five" personality traits.

\section{MODEL}

This study bases the relationship between personality and budget shortfalls on the "Cultural Theory of Budgeting" (Wildavsky, 1975). Wildavsky describes budgets as "hypotheses" made by government leaders 
about the future. Budget gaps reflect a disparity between the demands on a government and the capabilities to fund these demands. Budgets themselves are reflections of a society's values and interests. Budgets are an attempt to apportion limited resources across needs, necessarily requiring the taking of revenues from some citizens and distributing them to others. There is always a demand for more funding; there is never enough money and the outcomes of the decisions are never fully understood by the individuals making the allocations. This necessarily generates conflict, which is resolved by the decisionmakers as to which destinations of the resources lead to the most desirable events (Wildavsky, 1975). They also serve as signals to both constituencies of the leadership and potential candidates who are competing for the leaders' role as decision maker.

According to the theory, budgeting is often the most important action that administrators perform. Budgeting, ideally would involve a rational process of prioritization of scarce resources towards the most valuable ends for a constituency. This involves both an evaluation of the merits of the goals, but also judgments of the viability of initiatives supporting these goals. These goals and judgments are influenced by the constituency who selects and dismisses individuals according to how well they represent their interests and maintain their trust. This alignment is facilitated by publicity, news and opportunistic behavior in competitors for the administrator's job. Politicians' behavior is typically aligned with what their constituencies see as normative behavior, even though it is easy to recall particular cases to the contrary (Kahneman, 2011).

While rational decision making may be seen as the optimal means of allocating scarce resources through budgeting, the nature of the activity prevents this from fully emerging. The process of developing budgets is complex, time is compressed and the administrators have limited rationality available for optimal decision making. As such "those who budget deal with their overwhelming burdens by adopting heuristic aids to their calculations" (Wildavsky, 1975).

Political leaders, in general tend to be reflections of their society (Hofstede, 2001), as such they are elected, coopted or tolerated as leaders because of their representation of characteristics their societies hold dear. Some leaders may need to spend resources to show that they meet or even exceed what they individually hold as valuable compared to their constituency's expectations of what an office holder should have for this position (Geddes, 1994). Even if the beliefs or personality characteristics were only instrumentally adopted in order to win their leadership position, the repetitive display moves an individual towards deep level adoption of these characteristics so that over time the individual does tend to see the characteristics as their own (Grandey, 2003).

\subsection{State Level Personality}

Every individual possesses a unique process for understanding and dealing with their world. These enduring internal or psychological structures which affect the way with which they interact with their environment are often referred to as "personality". A large component of these many characteristics which make up a personality are shared interpretive systems, known as culture. Culture as a means of interpretation, or "software of the mind" as Hofstede (2001) refers to it, presents groups of individuals both a platform for understanding stimuli, but also a shared foundation with which to communicate as well as coordinate action.

In this respect, groups and societies have been found to share personality characteristics (Smith et al., 2006). These shared personality characteristics may themselves lead to aggregate group level distinctions and may also give rise to different cultural practices and institutions which further distinguish one group from another (Hofstede and McCrae, 2004). Personalities are trait-like. While individual personality characteristics may vary within a culture, an individual's personality may change to some extent, but remain somewhat more stable as the person ages, particularly after age 30 (Roberts et al., 2006).

Building upon earlier work in cross cultural personality studies, Norman (1963) identified five dimensions of variation among fraternity acquaintances from a set of descriptors culled from the English language by Allport and Odbert (1936). Over the years, this five factor constellation description of personality has been seen as a stable factor structure across cultures, while individuals themselves vary in the levels of each factor (Smith et al., 2006). The five factors include: extraversion, agreeableness, conscientiousness, neuroticism and openness to new experience.

\subsection{Extraversion}

Extraversion represents the extent to which individuals are assertive, active, energetic, talkative, dominant and enthusiastic (Costa and McCrae, 1992). A person scoring highly on the Extraversion scale would tend to be cheerful, seek excitement and stimulation and like people and large groups. Likewise, people scoring 
low prefer to spend time alone and are seen to be reserved, quiet and independent.

Extraversion has been linked to cooperative behavior (LePine and Van Dyne, 2001) and a general social vitality as a member of a constellation of positive personality factors (Roberts et al., 2006). As an aggregate level personality factor, extraversion has been associated with socially negative outcomes such as divorce rates, corruption and crime (Hofstede, 2001), as extraverts may tend to focus on self at the expense of others (Hofstede, 2001). Given the conflicting views on extraversion, no effect is hypothesized for a relationship between extraversion and state budget gaps.

\subsection{Agreeableness}

Agreeableness characterizes one's interpersonal orientation. This is seen as being more trusting, forgiving, caring, altruistic and gullible. A high agreeableness individual represents someone who values cooperativeness and positive interpersonal relationships. Low Agreeableness individuals can be characterized as manipulative, self-centered and ruthless (Costa and McCrae, 1992). In a group context, agreeableness has been observed to avoid conflict by giving others higher performance ratings despite conflicting evidence (Raymond and Sharples, 2012). Likewise, when others violate rules or expectations, those with higher levels of agreeableness tend to forgive the transgressions more than those with lower levels of agreeableness (Steiner et al., 2012).

While these tendencies tend to provide better group relations, which may lead to more functional behavior towards group goals such as found in legislative activities (Milam et al., 2009), agreeableness may make an administrator more reluctant to challenge faulty proposals. While the ideal of group decision making is to generate higher quality decisions, groups possessing high degrees of cohesiveness often experience an inflated sense of optimism when faced with obvious dangers and often take extraordinary risks while failing to respond to clear warnings of danger (Scharff, 2005). Questioning opinions, assumptions or offering alternative choice risks generating conflict (Wildavsky, 1975).

While the act of government budgeting involves disbursing resources towards valuable initiatives, which would be consonant with the disposition of an individual high in agreeableness, a balanced budget requires the capture of resources from others. This conflict generating activity is particularly unwanted in an agreeable individual. In a state where the general tendency of individuals is to be more agreeable, the legislature is more likely to be composed of agreeable representatives, making this balancing activity more difficult.

\section{Hypothesis 1}

There is a positive relationship between state level agreeableness and the size of state budget gaps.

\subsection{Conscientiousness}

Conscientiousness is a personality dimension indicating a person's degree of persistence, hard work, organization and motivation in the pursuit of goal accomplishment. Conscientiousness is an indicator of an individual's volition or his/her ability to work hard (Barrick and Mount, 1991). Initial examination of the conscientiousness to crime connection led to the view of a relationship between conscientiousness and lawful behavior. Collins and Schmidt (1993) explained the relationship as a linkage between conscientiousness and the construct of integrity, which lead individuals to avoid criminal behavior. Recent work on conscientiousness suggests deeper domains within the construct involving orderliness and self-control (Roberts et al., 2005). Legislators, serving a constituency which is oriented towards orderliness and self-control, while themselves tending to possess such traits would tend to see budget issues as an issue of restraint and planning.

\section{Hypothesis 2}

There is a negative relationship between the state level conscientiousness and state budget gaps.

\subsection{Neuroticism}

Neuroticism represents a person's capability to adjust as well as their emotional stability. A person high in Neuroticism tends to experience emotions including anxiety, hostility, depression, self-consciousness, impulsiveness and vulnerability (Costa and McCrae, 1992). Some explanation for the cause of neuroticism has pointed towards a hyper sensitivity to negative outcomes. Gray explained this sensitivity as the close cognitive linkage between negative stimuli as signals of punishment (Gray, 1991). High neuroticism individuals displayed more negative emotions to stressful events (Bolger and Zuckerman, 1995). While this added sensitivity to negative events may serve to focus attention to fiscal problems in both the legislative as well as the state constituencies, the effect of impulsiveness and self-control leads to a competing view that neuroticism leads to an inability to address fiscal shortfalls in advance and effectively. No relationship is expected between neuroticism and state budget gaps. 


\subsection{Openness to New Experience}

Openness to new experience assesses one's intellectual curiosity and their drive to seek new experiences and explore novel ideas. A person high on openness tends to be creative, innovative, imaginative, reflective and untraditional. Conversely, low openness tends to be conventional and narrow in interests (Costa and McCrae, 1992). Some relationships with openness have been noted with respect to fiscal issues at the individual level.

Kosek (1995) in a study of pro-social behavior found a positive relationship between openness to new experience and personal sense of fiscal responsibility to others. More recent discussions of potential higher order factors from the Big Five suggest two main factors, one of which is usually based heavily on the openness to new experience factor of the Big Five (Vecchione et al., 2011).

Digman (1997) proposes two factors underlying the Big Five which he coined the "Alpha" and the "Beta". Alpha is related to the shared variance of neuroticism, conscientiousness and agreeableness. The Beta is based on openness to new experience and extraversion. DeYoung (2006) has since developed a refinement, naming the two factors Stability and Plasticity, arguing that Stability is related to promoting constancy and plasticity is related to exploration.

In the context of legislation and budget management, a propensity towards change, exploration and a focus on individual level fiscal responsibility would displace strategies focusing on making existing activities more efficient and exploiting current ideas. Decision makers would be more attracted to untested transformational agendas rather than incremental variations on current initiatives. Budget cutting being an operational activity would be less an option for those with high openness to new experience.

\section{Hypothesis 3}

Openness to new experience will be positively related to state budget gap.

\subsection{Interaction between Agreeableness and Conscientiousness}

Recent work with the factors agreeableness and conscientiousness have suggested unique interactions with the two constructs. Milam et al. (2009) identified a pro social work behavior in those possessing both high conscientiousness as well as high agreeableness. Recent work in self-control and behavior regulation found an unexpected relationship between anger and agreeableness, where highly agreeable individuals, if low in conscientiousness, showed a higher level of anger. Conscientiousness qualified the moderating relationship of agreeableness to anger and self-control (Jensen-Campbell et al., 2007).

In the context of state legislative activity, conscientiousness will be more effective in resolving budgetary issues where high agreeableness affords the capability to focus on cooperative behavior between the competing interests for state resources and their respective representatives. Conversely, low agreeableness may impede cooperation towards budget management and the tradeoffs required of the participants serve as vulnerabilities, reducing the ability for participants to make concessions for the larger goals.

\section{Hypothesis 4}

There will be an interaction effect between agreeableness and conscientiousness relating to state budget gap such that as there is an increase in agreeableness, there will be an increasingly negative relationship between conscientiousness and state budget gap.

\section{METHOD}

Per capita GDP was calculated using population counts and reported state GDP's (USCB, 2012). Unilateral executive authority has been implicated in interference in state legislature budgetary formulation, where governors co-opted the process for short term electoral gains (Krause and Melusky, 2012). To separate effects for effects of previous budgetary influences, the previous year's (2010) budget was also used as a control, to separate legacy effects of the recession on the subsequent budgets.

Data for the Big Five personality variables were obtained from Rentfrow et al. (2008) survey results. Their survey consists of an online questionnaire administered to respondent volunteers. Complete data were received from 619,397 respondents over the period between December 1999 and January 2005. While convenience sampling such as this risks failure in capturing a representative sample of the population in question, the representativeness of the sample from each state in the U.S. with respect to the U.S. Census Bureau's estimates of the population of each state was directly proportional $(r=0.98)$. In general, the survey matched the U.S. population at large (Rentfrow et al., 2008). The survey questionnaire used the BFI's 44 short statements designed 
to assess the prototypical traits of each of the Five Factor Model dimensions (John and Srivastava, 1999).

State budget gaps were taken from the Center on Budget and Policy Priorities, based on the gaps that the states faced at the close of the previous fiscal year (Oliff et al., 2012). Thirty-one states complete their fiscal year on July 1st. The remaining 19 budget gap percentages were based on the assumptions used in the states' 2013 budget plans. The dependent variable is the three year average of the budget gap percentages of the states' general fund. The three years averaged were 2011 through 2013 as being the most recent and relatively stable with respect to policy and economic changes.

\section{DATA ANALYSIS AND RESULTS}

Data for the personality variables were normalized. A descriptive statistical analysis was performed on the data, revealing strong skew and kurtosis values for the variables of 2011-2013 Budget Gaps $(1.141,2.752)$ and Agreeableness (-1.694, 6.030). Agreeableness was square transformed. Both the 2011-13 Budget gap variable and the 2010 Budget Gap were converted to rank order. Given the small sample size $(n=50)$ and the risk of one outlier influencing the generalizability of the findings of this analysis, the decision was made to convert the state data into ordinal values to minimize the influence of strong outliers while preserving the data as the entire population (Kenney, 1987).

The correlations show relationship patterns between the personality dimensions as previous studies using the Big 5 Inventory (Barrick and Mount, 1991). One variable, neuroticism, does not show the negative correlation with conscientiousness and the positive relationship with agreeableness and openness found in other studies, as shown in Table $\mathbf{1 .}$

A first regression was performed using the controls to serve as a comparison for seeing the added variance prediction of the personality variables in the model. This yielded an adjusted R square of 0.413 ( $\mathrm{p}<0.001)$. Per Capita GDP, state population did not yield significance in the testing $(p>0.10)$, while previous state years' budget gap showed a significant relationships to succeeding years' budget gap $(\mathrm{p}<0.001)$.

To see if there is a significant improvement in explanatory power by including the five personality factors, a second regression including the Big Five personality variables was performed, yielding an $\mathrm{R}$ square of 0.539 , a difference of 0.091 . This failing to show significance at the 0.10 level $(p=0.166)$. Per capita GDP and population failed to show significance. As hypothesized, a significant relationships between state budget gap and agreeableness with a standardized beta of 0.361 emerged, significant at the $p<0.05(p=0.025)$. The extraversion variable showed no significant relationship with state budget gaps $(\mathrm{p}=0.562)$, as expected.

Supporting hypothesis 3 , the variable conscientiousness showed a negative relationship with state budget gaps, with a standardized beta of $-2.80,(\mathrm{p}=$ 0.083 ). Neuroticism was not significantly related to state budget gaps $(\mathrm{p}=0.278)$, as expected. The variable representing openness to new experience was positively related to state budget gaps, with a standardized beta of 0.291 , significant at the $\mathrm{p}<0.05$ level $(\mathrm{p}=0.032)$.

A third regression was performed, adding an interaction term consisting of conscientiousness and agreeableness to the full model, yielding an R square of 0.629 . This led to a change of 0.089 , showing a significance at the 0.01 level $(\mathrm{p}=0.003)$, suggesting that with the interaction term between conscientiousness and agreeableness, the personality model explains a significant portion of variance in levels of state budget shortfalls. As with the previous analysis, the extraversion term failed to show any significance $(\mathrm{p}=0.873)$.

$\underline{\text { Table 1. Descriptive statistics and correlations for all variables }}$

\begin{tabular}{|c|c|c|c|c|c|c|c|c|c|c|c|}
\hline & \multirow[b]{2}{*}{ Variable } & \multirow[b]{2}{*}{ M } & \multirow[b]{2}{*}{ SD } & \multicolumn{8}{|c|}{ Correlation } \\
\hline & & & & 1 & 2 & 3 & 4 & 5 & 6 & 7 & 8 \\
\hline 1 & 2011-13 Bdgt Gap & & & & & & & & & & \\
\hline 2 & 2010 Budget Gap & & & $0.629 * *$ & & & & & & & \\
\hline 3 & Private GDP & $1.68 \mathrm{E}+05$ & $3.06 \mathrm{E}+05$ & $0.366 * *$ & $0.293 *$ & & & & & & \\
\hline 4 & Population 2010 & $5.93 E+06$ & $6.53 \mathrm{E}+06$ & $0.372 * *$ & $0.268+$ & $0.982 * *$ & & & & & \\
\hline 5 & Extraversion & & & -0.086 & -0.213 & 0.004 & 0.028 & & & & \\
\hline 6 & Agreeableness & & & 0.088 & -0.132 & 0.003 & 0.063 & $0.483^{* *}$ & & & \\
\hline 7 & Conscientiousness & & & 0.004 & -0.109 & 0.093 & 0.169 & $0.392 * *$ & $0.629 * *$ & & \\
\hline 8 & Neuroticism & & & -0.079 & -0.017 & 0.098 & 0.094 & -0.160 & -0.163 & -0.267 & \\
\hline 9 & Openness & & & $0.322 *$ & $0.262+$ & $0.313^{*}$ & $0.291 *$ & $-0.324 *$ & $-0.350 *$ & 0.006 & 0.093 \\
\hline
\end{tabular}

Note. All tests are two tailed. $\mathrm{N}=50$ 
Table 2. Coefficients ${ }^{\mathrm{a}}$

\begin{tabular}{|c|c|c|c|c|c|c|}
\hline \multirow[b]{2}{*}{ Mod } & & \multicolumn{2}{|c|}{ Unstandardized coefficients } & \multicolumn{2}{|c|}{ Standardized coefficients } & \multirow[b]{2}{*}{ Sig. } \\
\hline & & $\mathrm{B}$ & Std. Error & Beta & $\mathrm{t}$ & \\
\hline \multirow[t]{4}{*}{1} & (Constant) & 7.252 & 3.518 & & 2.061 & 0.045 \\
\hline & State per Capita GDP & $-2.35 \mathrm{E}-05$ & 0.000 & -0.483 & -0.821 & 0.416 \\
\hline & State Population & $1.58 \mathrm{E}-06$ & 0.000 & 0.689 & 1.181 & 0.244 \\
\hline & Previous Budget Gap & 0.586 & 0.114 & 0.586 & 5.139 & 0.000 \\
\hline \multirow[t]{9}{*}{2} & (Constant) & -5.692 & 6.874 & & -0.828 & 0.412 \\
\hline & State per Capita GDP & $-2.94 \mathrm{E}-05$ & 0.000 & -0.606 & -0.967 & 0.339 \\
\hline & State Population & $1.76 \mathrm{E}-06$ & 0.000 & 0.773 & 1.231 & 0.225 \\
\hline & Previous Budget Gap & 0.543 & 0.077 & 0.543 & 4.737 & 0.000 \\
\hline & Extraversion & 0.303 & 1.882 & 0.02 & 0.161 & 0.873 \\
\hline & Agreeableness & 0.731 & 0.315 & 0.361 & 2.318 & 0.025 \\
\hline & Conscientiousness & -4.17 & 2.346 & -0.28 & -1.777 & 0.083 \\
\hline & Neuroticism & -1.822 & 1.659 & -0.122 & -1.098 & 0.278 \\
\hline & Openness to New Experience & 4.319 & 1.937 & 0.291 & 2.230 & 0.031 \\
\hline \multirow[t]{10}{*}{3} & (Constant) & -0.456 & 6.466 & & -0.071 & 0.944 \\
\hline & State per Capita GDP & $-3.80 \mathrm{E}-05$ & 0.000 & -0.783 & -1.369 & 0.179 \\
\hline & State Population & $2.13 \mathrm{E}-06$ & 0.000 & 0.938 & 1.637 & 0.109 \\
\hline & Previous Budget Gap & 0.595 & 0.105 & 0.595 & 5.640 & 0.000 \\
\hline & Extraversion & 0.475 & 1.711 & 0.032 & 0.278 & 0.783 \\
\hline & Agreeableness & 0.523 & 0.294 & 0.259 & 1.780 & 0.083 \\
\hline & Conscientiousness & 5.622 & 3.779 & 0.378 & 1.488 & 0.145 \\
\hline & Neuroticism & -3.078 & 1.560 & -0.207 & -1.973 & 0.055 \\
\hline & Openness to Experience & 2.837 & 1.823 & 0.191 & 1.557 & 0.127 \\
\hline & A_C interaction & -0.574 & 0.183 & -0.708 & -3.138 & 0.003 \\
\hline
\end{tabular}

a. Dependent Variable: AvgBudgetgap11_13

The agreeableness term maintained a positive relationship with state budget gaps, with a standardized beta of 0.259 , significant at the $\mathrm{p}<0.10$ level $(\mathrm{p}=0.083)$. This fully supports hypothesis 1 . Conscientiousness did not maintain significance in the third regression $(\mathrm{p}=0.145)$, with a standardized beta of 1.488 , leaving hypothesis 2 with only partial support from the model omitting the interaction term.

Neuroticism did show a negative relationship to state budget gaps with a standardized beta of -0.207 , significant at the $\mathrm{p}<0.10$ level $(\mathrm{p}=0.055)$. Openness to new experience failed significance at the $p<0.10$ level ( $p$ $=0.127$ ), leaving only partial support for hypothesis 3 .

The interaction term consisting of agreeableness and conscientiousness suggests a negative relationship between agreeableness, conscientiousness and state budget gaps. As agreeableness increases the relationship between conscientiousness and state budget gap is increasingly negative $(\mathrm{p}=0.003)$, with a standardized beta of -0.708 (Table 2).

\section{DISCUSSION AND CONCLUSION}

A key motivation of this paper was to examine if there is a relationship between regional-level personality and government activities. The results of this study suggest that there is a multichannel process where personality affects behaviour, which leads to state level effects. This aggregated personality affects the representation of characteristics geographically. The hypotheses offered for this study suggest direct effects between personality and state budgetary outcomes, but personality is also instrumental in the creation of institutions, which also affect behaviour. These institutions shape social norms that have arisen from these personality characteristics and perpetuate these cognitive features in a population.

This process was examined by Rentfrow et al. (2008) in their Theory of the Emergence of Geographic Persistence of Personality Traits. Our study has examined one avenue from which the institutions may be affected by personality traits, the budget making activity of governments. At an individual level, conscientiousness is associated with self-control, persistence and goal orientations (Roberts et al., 2006). Groups and populations consisting of high conscientious individuals may be more in line with setting and maintaining budgetary discretion, but the influence of 
agreeableness and the interaction effect with conscientiousness points towards an effect where goal orientations rely on a level of consensus to achieve needed outcomes in order to have an effect.

Much as Michel's famous marshmallows study, higher conscientious populations may be able to defer gratification for even an uncertain future pay off. There may be an implicit understanding among the decision makers that this is an important goal and as a result, are able to manage to avoid budget gaps with more success than population possessing lower conscientiousness. Agreeableness shows a positive relationship with budgetary gaps, but only to the extent that it interacts with conscientiousness, suggesting that agreeableness facilitates cooperation towards particular goals. Conscientiousness may serve as a direction for this goal attainment, so agreeably-conscientiousness populations seem to be more focused on budget issues and more able to coordinate efforts towards achieving a balanced budget.

The emergence of neuroticism as a predictor of budget performance, when included with the agreeably conscientious factor leads to the possibility that two independent functions driving budget concerns in a population may exist-concern for orderliness through planning ahead from the conscientious personality influences and a concern for avoiding negative outcomes, from the extra sensitivity to negative consequences related to neuroticism. The feeling associated with high neuroticism personality traits may magnify the downsides associated with failing to meet budget goals. The openness to new experience relationship to budget gaps loses significance when the agreeably conscientious factoris introduced. This shows some consistency with the claims of the super-ordinal personality factor combining agreeableness, conscientiousness and openness to new experience as components of positive personality traits, making for more rational and enduring decisions (Vecchione et al., 2011).

Political science research in liberal to conservative personality characteristics offers support for the observed outcomes. Carney et al. (2008) conducted a multimethod study of individuals' self-reported political preference along with BFI self-reported, behaviourally observed and personal possession assessment of individuals, finding a relationship between conservatism and conscientiousness, openness to new experience and liberalism. This difference in political perspectives has been linked to governor/legislature budget performance where conservative leadership maintains more budgetary management and acts to cut funding more readily when faced with potential shortfalls (Dometrius and Wright, 2010).

One limitation of this study is the small sample size. While this study is the entire population of U.S. states, many states are relatively large and consist of culturally diverse, yet stable populations. Breaking the states into sub-regions would provide a finer grained examination of the personality to legislation relationship. This in turn may provide a clearer empirical testing. Further studies may also incorporate governor personality as an intervening variable. This could be done using archival governor State of the State addresses (Rubenzer et al., 2000), extending on the personality theory proposed by Rentfrow et al. (2008). This would clarify the process in which personality manifests itself from the population to the institutions that both reflect and shape a region's personality characteristics.

\section{REFERENCES}

Allport, G. and H. Odbert, 1936. Trait-names: A psycholexical study. Psychol. Monographs, 47: i-171. DOI: 10.1037/h0093360

Barrick, M.R. and M.M. Mount, 1991. The big five personality dimensions and job performance: A Meta-Analysis. Personnel Psychol., 44: 1-26. DOI: 10.1027/1614-0001.29.1.11

Bolger, N. and A. Zuckerman, 1995. A Framework for Studying Personality in the Stress Process. J. Personality Social Psychol., 69: 890-902. 10.1037/0022-3514.69.5.890

Buffet, W., 2013. Berkshire Hathaway Letters to Shareholders. 2nd Edn., Max Olson, ISBN-10: 0615975070, pp: 752.

Carney, D.R., J.T. Jost, S.D. Gosling and J. Potter, 2008. The secret lives of liberals and conservatives: Personality profiles, interaction styles and the things they leave behind. Political Psychology, 29: 807840. DOI: 10.1111/j.1467-9221.2008.00668.x

Collins, J.M. and F.L. Schmidt, 1993. Personality, integrity and white collar crime: A construct validity study. Personnel Psychol., 46: 295-311. DOI: 10.1111/j.1744-6570.1993.tb00875.x

Costa, P.T. and R.R. McCrae, 1992. NEO PI-R: Revised NEO personality inventory and NEO Five-Factor Inventory (NEO-FFI). PAR.

DeYoung, C.G., 2006. Higher-order factors of the big five in a multi-informant sample. J. Personality Social Psychol., 91: 1138-1151 DOI: 10.1037/00223514.91.6.1138 
Digman, J.M., 1997. Higher-order factors of the big five. J. Personality Social Psychol., 73: 1246-1256. DOI: 10.1037/0022-3514.73.6.1246

Dometrius, N.C. and D.S. Wright, 2010. Governors, legislatures and state budgets across time. Political Res. Q., 63: 783-795. DOI: $10.1177 / 1065912909334428$

Eide, S., 2013. Is Good Is good faith bargaining good policy. Public Sector Inc.

Geddes, B., 1994. Politician's Dilemma: Building State Capacity in Latin America. 1st Edn., University of California Press, ISBN-10: 0520918665, pp: 246.

Grandey, A.A., 2003. When "The show must go on": Surface acting and deep acting as determinants of emotional exhaustion and peer-rated service delivery. Acad. Manage. J., 46: 86-96. DOI: $10.2307 / 30040678$

Gray, J.A., 1981. A Critique of Eysenck's Theory of Personality. In: A Model of Personality, Eysenck, H.J. (Ed.)., Springer Berlin Heidelberg, ISBN-10: 978-3-642-67785-4, pp: 246-276.

Hofstede, G. and R. McCrae, 2004. Personality and culture revisited: Linking traits and dimensions of culture. Cross Cultural Res., 38: 52-88. DOI: 10.1177/1069397103259443

Hofstede, G., 2001. Culture's Consequences: Comparing Values, Behaviors, Institutions and Organizations across Nations. 2nd Edn., SAGE Publications, Inc, ISBN-10: 0803973241, pp: 616.

Jensen-Campbell, L.A., J.M. Knack, A.M. Waldrip and S.D. Campbell, 2007. Do big five personality traits associated with self-control influence the regulation of anger and aggression? J. Res. Personality, 41: 403-424. DOI: 10.1016/j.jrp.2006.05.001

John, O.P. and S. Srivastava, 1999. The Big Five Trait Taxonomy: History, Measurement and Theoretical Perspectives. In: Handbook of Personality: Theory and Research, Pervin, L.A. and O.P. John (Eds.)., New York, Guilford, pp: 102-138.

Kahneman, D., 2011. Thinking, Fast and Slow. 2nd Edn., Penguin Books Limited, ISBN-10: 0141918926, pp: 512.

Kenney, D., 1987. Statistics for the social and behavioral sciences. Little, Brown.

Kosek, R.B., 1995. Measuring prosocial behavior of college students. Psychol. Reports, 77: 739-742. DOI: $10.2466 /$ pr0.1995.77.3.739
Krause, G.A. and B.F. Melusky, 2012. Concentrated powers: Unilateral executive authority and fiscal policymaking in the American States. J. Politics, 74: 98-112. DOI: 10.1017/S0022381611001149

LePine, J.A. and L. Van Dyne, 2001. Peer responses to low performers: An attributional model of helping in the context of groups. Acad. Manage. Rev., 26: 6784. DOI: 10.5465/AMR.2001.4011953

Milam, A.C., C. Spitzmueller and L.M. Penney, 2009. Investigating individual differences among targets of workplace Incivility. J. Occupational Health Psychol., 14: 58-69. DOI: 10.1037/a0012683

Norman, W.T., 1963. Toward an adequate taxonomy of personality attributes: Replicated factor structure in peer nomination personality ratings. J. Abnormal Soc. Psychol., 66: 574-583. DOI: 10.1037/h0040291

Oliff, P., C. Mai and V. Palacios, 2012. States continue to feel recession's impact. Center Budgetand Policy Priorities. Retrieved.

Raymond, R. and D. Sharples, 2012. The impact of agreeableness and rating context on the evaluation of poor performance. J. Occupat. Organizat. Psychol., 81: 42-59. DOI: 10.1348/20448325.002002

Rentfrow, P.J., Gosling, S.D. and J. Potter, 2008. A theory of the emergence, persistence and expression of psychological variation in psychological characteristics. Perspect. Psychol. Sci., 3: 339-369. DOI: 10.1111/j.17456924.2008.00084.x

Roberts, B.W., K.E. Walton and W. Viechtbauer, 2006. Patterns of mean-level change in personality traits across the life course: A metaanalysis of longitudinal studies. Psychol. Bullet., 126: 3-27. DOI: 10.1037/0033-2909.132.1.1

Roberts, B.W., O.S. Chernyshenko, S. Stark and L.R. Goldberg, 2005. The structure of conscientiousness: An empirical investigation based on seven major personality questionnaires. Personnel Psychol., 58: 103-109. DOI: 10.1111/j.1744-6570.2005.00301.x

Rubenzer, S.J., T.R. Faschingbauer and D.S. Ones, 2000. Assessing the U.S. presidents using the revised neo personality inventory. Assessment, 7: 403-420. DOI: 10.1177/107319110000700408

Scharff, M.M., 2005. Understanding world com's accounting fraud: Did groupthink play a role. J. Leadership Organizat. Study, 11: 109-118. DOI: 10.1177/107179190501100309 
Smith, P.B., M.H. Bond and C. Kagitcibasi, 2006. Understanding Social Psychology across Cultures: Living and Working in a Changing World. 2nd Edn., SAGE Publications, ISBN-10: 1412903661, pp: 323.

Steiner, M., M. Allemand and M.E. McCullough, 2012. Do agreeableness and neuroticism explain age difference in the tendency to forgive others. Personal. Society Psychol. Bullet., 38: 441-453. DOI: $10.1177 / 0146167211427923$
USCB, 2012. U.S. Census Bureau. Am. City Bus. J.

Vecchione, M., G. Alessandri, C. Barbaranelli and G. Caprara, 2011. Higher-order factors of the big five and basic values: Empirical and theoretical relations. British J. Psychol., 102: 478-498. DOI: 10.1111/j.2044-8295.2010.02006.x

Wildavsky, A., 1975. Budgeting: A comparative theory of budgetary processes. J. Polit., 38: 1065-1066. DOI: $10.2307 / 2129522$ 